\title{
Modelos de afilamento e forma dos fustes de eucalipto, em diferentes qualidades de sítio
}

\author{
Saulo Jorge TÉO ${ }^{1 *}$, Eder Pereira MIGUEL ${ }^{2}$, Rodrigo Geroni Mendes NASCIMENTO² \\ ${ }^{1}$ Universidade do Oeste de Santa Catarina, Xanxerê, SC, Brasil. \\ ${ }^{2}$ Departamento de Engenharia Florestal, Universidade de Brasília (UnB), Brasília, Distrito Federal, Brasil. \\ ${ }^{3}$ Universidade Federal Rural da Amazônia, Belém, PA, Brasil. \\ *E-mail: sauloteo@yahoo.com.br
}

Recebido em fevereiro/2018; Aceito em abril/2018.

\begin{abstract}
RESUMO: Este trabalho teve como objetivo ajustar e selecionar modelos de afilamento para estimar diâmetros, volume por seção e volume acumulado com casca, ao longo do tronco de árvores de Eucalyptus grandis Hill ex. Maiden, em Rio Verde - GO, para estudar a forma dos fustes das árvores em diferentes classes de sítio. Foram cubadas rigorosamente pelo método de Smalian, 812 árvores em um povoamento florestal cuja densidade inicial foi de 1.111 árvores por hectare, com idade de 80 meses. Os modelos de afilamento testados foram os Polinômios de $2^{\circ}$ e de $5^{\circ}$ Graus e o Polinômio de Potências Fracionárias e Inteiras de Hradetzky. A função de afilamento mais acurada para estimar os diâmetros e volumes por seção, ao longo do fuste das árvores foi o Polinômio de Hradetzky, para todas as classes de sítio testadas. No entanto, para estimar os volumes acumulados, a função de afilamento de melhor desempenho foi o Polinômio de $5^{\circ}$ Grau para as classes de sítio II e III, e o Polinômio de Hradetzky, para a classe de sítio I. Os fustes das árvores de Eucalyptus grandis apresentam melhor forma nos sítios de melhor qualidade, enquanto na pior classe de sítio, apresentam maior conicidade.
\end{abstract}

Palavras-chave: modelos polinomiais, perfil do fuste, Eucalyptus grandis.

\section{Taper models and stem form of eucalyptus, in different site qualities}

\begin{abstract}
The objective of this paper was fitting and selecting taper models to estimate diameters, volume section and accumulated volume outside bark, throughout stem of Eucalyptus grandis Hill ex. Maiden trees, in Rio Verde - GO, Brazil, as well as, study the stem form of the trees at different site classes. Altogether, it was measured by Smalian volume calculation procedure, 812 trees of a forest stand with initial density of 1,111 trees per hectare and age of 80 months. The taper models tested was the $2^{\circ}$ and $5^{\circ}$ Degree Polynomial and the Hradetzky Polynomial of Fractioned and Entire Potencies. The most accurate taper function for estimating diameters and volume section outside bark, throughout stem was Hradetzky Polynomial function, for all site classes tested. However, to estimate accumulated volume outside bark, the best performance was the $5^{\circ}$ Degree Polynomial taper function for II and III site classes, and the Hradetzky Polynomial, for the site class I. The stems of the Eucalyptus grandis trees present better form in the sites with better quality, whereas in the poorest site class the stems are more conical.
\end{abstract}

Keywords: polynomial models, stem profile, Eucalyptus grandis.

\section{INTRODUÇÃO}

A forma do fuste das árvores diz respeito à sua figura, configuração externa ou aspecto exterior de seu corpo, a qual é definida pelo processo de crescimento do diâmetro e da área seccional ao longo do tronco da árvore. Todavia, não se pode medir a forma de uma árvore ou tora como se faz com o diâmetro ou a altura, somente estabelecer índices que a representam. A captação da forma torna-se possível pela medição de diâmetros a distintas alturas, e sua expressão se dá por meio de quocientes de forma, fatores de forma e funções de afilamento.

Para maximizar a remuneração e valor econômico da madeira, é importante compreender a variabilidade de seus atributos de qualidade, para a maioria das espécies florestais comerciais. A forma é um dos mais importantes parâmetros externos de qualidade do fuste, frequentemente utilizado como critério de sortimento florestal. Fustes com forma inferior, tais como aqueles que apresentam afilamento e curvatura acentuados, são usualmente relacionados com baixo rendimento em serrarias, propriedades mecânicas da madeira ruins e alto custo de processamento (TONG; ZHANG, 2008).

Quando disponíveis os volumes por sortimento de um povoamento florestal, é possível planejar a venda da madeira de forma otimizada, visando uma maior valoração pelo mercado consumidor, maximizando os lucros. Os modelos de afilamento possibilitam que o planejamento da produção, da logística de transporte e comercialização, seja feito em função do sortimento, contabilizado em número de toras destinadas a cada produto específico (ASSIS et al., 2002), além de constituírem ferramenta importante para a gestão da informação em empresas florestais (EISFELD et al., 2004).

Não existe uma única classificação de sortimento possível e válida para todas as empresas florestais, tampouco uma função de afilamento universal para todas as espécies e sítios florestais, assim deve-se estudar a forma e definir o sortimento para cada caso, com suas próprias peculiaridades de utilização da madeira (AHRENS; HOLBERT, 1981). Ao longo das últimas duas décadas a utilização de funções de afilamento 
para representar o perfil do fuste e estimar volumes por sortimento de árvores intensificou-se ao despertar interesse de pesquisadores florestais brasileiros, sendo uma técnica que vem sendo aperfeiçoada e divulgada até a atualidade por diversos pesquisadores (MIGUEL et al., 2011; FAVALESSA et al., 2012a; FAVALESSA et al., 2012b; SOUZA et al., 2012; YOSHITANI JUNIOR et al., 2012; KOHLER et al., 2013; LANSSANOVA et al., 2013; TÉO et al., 2013; DAVID et al., 2014; MÔRA et al., 2014).

As equações de afilamento devem ser preferidas, na maior parte das vezes, às equações de volume, pois além de fornecer estimativas do volume total, podem estimar volume comercial a qualquer altura ou diâmetro especificado, portanto, é imprescindível avaliar a precisão e acurácia das estimativas de volume ao longo do tronco das árvores e não somente para os volumes totais.

Muitas árvores, especialmente as coníferas e algumas folhosas, se caracterizam por um fuste central definido, este tipo de fuste se denomina excurrente. Por outro lado, a maioria das folhosas apresenta fuste definido somente em sua porção inferior, até o início da copa, essa característica se perde devido à grande ramificação, a esta forma denomina-se de deliquescente. Todas as árvores apresentam uma forma típica de seu fuste, a qual varia com a espécie, idade, sítio, posição sociológica, densidade do povoamento, intervenções silviculturais como desbaste e poda, e até estresses mecânicos, como os causados pelo efeito do vento sobre a árvore (AHRENS; HOLBERT, 1981).

Quanto ao efeito sobre a forma do fuste de árvores de Pinus taeda, constatou-se que há menor afilamento e, portanto, melhor forma, para as maiores densidades iniciais (NOGUEIRA et al., 2008) e idades mais avançadas (TÉO et al., 2013). Para Eucalyptus grandis, a adubação melhorou levemente a forma dos fustes, tornando-os mais cilíndricos (FERREIRA; SILVA, 2002). Como as funções de afilamento expressam a forma do tronco das árvores, verificou-se a melhor qualidade do ajuste das funções de afilamento quando realizadas por classe de idade (QUEIROZ et al., 2008; KOHLER et al., 2013; FIGUEIREDO FILHO et al., 2014; KOHLER et al., 2016) classe de diâmetro (ASSIS et al., 2002; EISFELD et al., 2008), classe de quocientes e fatores de forma (SOUZA et al., 2012; DAVID et al., 2014) e diferentes sítios (FIGUEIREDO et al., 2006).

Os objetivos desta pesquisa foram ajustar e selecionar modelos de afilamento para estimar diâmetros e volumes com casca, ao longo do tronco de árvores de Eucalyptus grandis Hill ex. Maiden, em Rio Verde, Goiás, com a finalidade de estudar o comportamento da forma dos fustes das árvores de diferentes classes de sítio.

\section{MATERIAL E MÉTODOS}

\section{1. Área de estudo}

Os dados do presente estudo foram obtidos em um plantio de Eucalyptus grandis pertencente à COMIGO - Cooperativa Mista dos Produtores Rurais do Sudoeste Goiano Ltda., Fazenda Florestal II, localizada na Rod. BR 060 km 397 Zona Rural, no município de Rio Verde, no Estado de Goiás, a 748 metros de altitude, possuindo as seguintes coordenadas geográficas: latitude $17^{\circ} 51^{\prime} 27^{\prime} \mathrm{S}$ e longitude $51^{\circ} 4^{\prime} 12^{\prime} \mathrm{W}$. Na região predominam Latossolos Vermelho Escuro e VermelhoAmarelo Distróficos, com horizonte A de moderado a médio, horizonte B Latossólico, textura argilosa.
O clima, segundo a classificação de Köppen, é do tipo Aw, zona tropical, com inverno seco. Há duas estações bem definidas: uma seca, que corresponde ao outono e inverno, do mês de maio ao mês de setembro e a outra úmida, correspondendo ao período de primavera e verão. A precipitação média anual é de $1.800 \mathrm{~mm}$ e temperatura média anual de $22,1^{\circ} \mathrm{C}$ (ALVARES et al., 2013).

\subsection{Caracterização dos dados}

O espaçamento inicial do plantio foi de $3 \times 3$ metros (1.111 árvores por hectares). Na oportunidade foram utilizadas mudas clonais produzidas na própria empresa e a implantação do povoamento foi realizada em janeiro de 2007 , sendo realizado o corte raso em setembro de 2013, oportunidade essa em que foram medidas as árvores. Dessa maneira, a idade das árvores utilizadas nesta pesquisa é de 6 anos e 8 meses, ou 80 meses.

A classificação de sítios para este povoamento de Eucalyptus grandis foi realizada por meio de método direto, com a variável altura dominante $\left(h_{d o m}\right)$, ou seja, altura média das 100 árvores mais grossas por hectare, como indicadora da qualidade do sítio, obtida por meio de inventário florestal contínuo. A construção das curvas anamórficas de índice de sítio se deu pela representação da $h_{d o m}$ ao longo do desenvolvimento do povoamento, por meio do método da curva guia, a qual foi representada pela equação 1 .

$$
\ln h_{d o m}=3,32642-1,47204 \frac{1}{I}
$$

(Equação 1)

em que: $h_{d o m}=$ altura dominante, em m; $I=$ idade, em ano; $\ln =$ logaritmo natural (base $e=2,718281829 \ldots$ ).

As estatísticas de ajuste e precisão da equação 1 aos dados de idade e $h_{\text {dom }}$ dos povoamentos de Eucalyptus grandis foram de $R_{a j .}^{2}=0,92285$ e $s y x \%=4,15$, já o seu fator de correção devido à discrepância logarítmica foi de $F_{M}=$ 1,0045. Foram definidas 3 classes de sítio para a idade de referência de 7 anos, onde os índices de sítio foram: Classe de Sítio I = 31,25 m; Classe de Sítio II = 28,75 m; e Classe de Sítio III $=26,25 \mathrm{~m}$.

Ao todo, 812 árvores, das classes de sítio I, II e III, foram abatidas e submetidas à cubagem rigorosa para obtenção de seus volumes. A Tabela 1 contém a distribuição das árvores de Eucalyptus grandis cubadas, nas diferentes classes de sítio, bem como, os valores de diâmetro à altura do peito médio $(\bar{d})$, diâmetro máximo $\left(d_{\text {máx }}\right)$, diâmetro mínimo $\left(d_{\text {mín }}\right)$, altura total média $(\bar{h})$, altura máxima $\left(h_{\text {máx }}\right)$ e mínima $\left(h_{m i ́ n}\right)$.

Tabela 1. Diâmetros, alturas e número de árvores de Eucalyptus grandis, cubadas por classe de sítio, em Rio Verde, Goiás.

Table 1. Diameter, height and number of Eucalyptus grandis trees measured by site class, in Rio Verde, Goiás.

\begin{tabular}{cccc}
\hline \multirow{2}{*}{ Variável } & \multicolumn{3}{c}{ Classe de sítio } \\
\cline { 2 - 4 } & $\mathrm{I}$ & $\mathrm{II}$ & $\mathrm{III}$ \\
\hline $\mathrm{n}^{0}$ de árvores & 271 & 271 & 270 \\
$\bar{d}(\mathrm{~cm})$ & 15,44 & 15,04 & 14,85 \\
$d_{\text {máx }}(\mathrm{cm})$ & 21,75 & 21,83 & 20,59 \\
$d_{\min }(\mathrm{cm})$ & 6,65 & 6,35 & 7,20 \\
$\bar{h}(\mathrm{~m})$ & 27,63 & 26,77 & 25,57 \\
$h_{\text {máx }}(\mathrm{m})$ & 33,10 & 31,80 & 30,50 \\
$h_{\text {mín }}(\mathrm{m})$ & 11,10 & 12,90 & 14,10 \\
\hline
\end{tabular}


Foi utilizado o método analítico de Smalian para obtenção do volume das árvores, onde as posições de medição do diâmetro ao longo do fuste foram definidas de maneira absoluta, desconsiderando-se a altura de toco de $0,1 \mathrm{~m}$. Foram medidos os diâmetros a $0,1 \mathrm{~m}, 0,3 \mathrm{~m}, 0,5 \mathrm{~m}, 0,7 \mathrm{~m}, 0,9 \mathrm{~m}, 1,1$ m, 1,3 m, 2,0 m (seção de 0,7 m), 3,0 m, 4,0 m e assim sucessivamente de 1 em 1 metro, até a altura total. $\mathrm{O}$ cálculo dos volumes de cada seção foi realizado utilizando-se a fórmula de Smalian e o volume da ponta foi obtido por meio da fórmula do volume do cone.

\subsection{Processamento dos dados}

Para o ajuste dos modelos de afilamento, foi considerada somente a porção do fuste a partir da altura de toco. O ajuste dos modelos de afilamento (Tabela 2) Polinômio de $2^{\circ}$ Grau e
Polinômio de $5^{\circ}$ Grau foi realizado por meio do método dos mínimos quadrados. No entanto, o Polinômio de Potências Fracionárias e Inteiras exigiu o teste de diversas potências para representar o perfil do tronco da árvore, as quais, neste trabalho, foram de 0,$00005 ; 0,0001 ; 0,0005 ; 0,001 ; 0,005$; 0,$01 ; 0,02 ; 0,03 ; 0,04 ; 0,05 ; 0,06 ; 0,07 ; 0,08 ; 0,09 ; 0,1 ; 0,2$; 0,$3 ; 0,4 ; 0,5 ; 0,6 ; 0,7 ; 0,8 ; 0,9 ; 1 ; 2 ; 3 ; 4 ; 5 ; 6 ; 7 ; 8 ; 9 ; 10 ; 15$; $20 ; 25 ; 30 ; 35 ; 40 ; 45 ; 50 ; 55 ; 60 ; 65 ; 70 ; 75 ; 80 ; 85 ; 90 ; 95$ e 100. As potências para compor o Polinômio de Potências Fracionárias e Inteiras foram selecionadas com base no procedimento de regressão passo a passo (stepwise regression), utilizando a abordagem de eliminação bidirecional, considerando um nível de significância de $1 \%(\alpha$ $=0,01)$ no teste de "F" parcial de cada coeficiente do modelo.

Tabela 2. Modelos de afilamento testados para árvores de Eucalyptus grandis, Rio Verde, Goiás.

Table 2. Taper functions tested for Eucalyptus grandis trees, Rio Verde, Goiás.

\begin{tabular}{ccc}
\hline Denominação & Autor(es) & Modelo \\
\hline Polinômio de $2^{\circ}$ Grau & Kozak et al. (1969) & $\frac{d_{i j}^{2}}{d_{j}^{2}}=\beta_{0}+\beta_{1}\left(\frac{h_{i j}}{h_{j}}\right)+\beta_{2}\left(\frac{h_{i j}}{h_{j}}\right)^{2}$ \\
Polinômio de $5^{\circ}$ Grau & Schöpfer (1966) & $\frac{d_{i j}}{d_{j}}=\beta_{0}+\beta_{1}\left(\frac{h_{i j}}{h_{j}}\right)+\beta_{2}\left(\frac{h_{i j}}{h_{j}}\right)^{2}+\beta_{3}\left(\frac{h_{i j}}{h_{j}}\right)^{3}+\beta_{4}\left(\frac{h_{i j}}{h_{j}}\right)^{4}+\beta_{5}\left(\frac{h_{i j}}{h_{j}}\right)^{5}$ \\
$\begin{array}{c}\text { Polinômio de Potências } \\
\text { Fracionárias e Inteiras }\end{array}$ & Hradetzky (1976) & $\frac{d_{i j}}{d_{j}}=\beta_{0}+\beta_{1}\left(\frac{h_{i j}}{h_{j}}\right)^{p 1}+\beta_{2}\left(\frac{h_{i j}}{h_{j}}\right)^{p 2}+\beta_{3}\left(\frac{h_{i j}}{h_{j}}\right)^{p 3}+\cdots+\beta_{n}\left(\frac{h_{i j}}{h_{j}}\right)^{p n}$ \\
\hline
\end{tabular}

$\overline{d_{i j}}=$ diâmetro na altura $h_{i j}(\mathrm{~cm}) ; d_{j}=$ diâmetro a $1,30 \mathrm{~m}$ do solo da j-ésima árvore $(\mathrm{cm}) ; h_{i j}=$ altura na posição $i$ do fuste da árvore $j(\mathrm{~m}) ; h_{j}=$ altura total da árvore $j(\mathrm{~m}) ; \beta_{0}, \beta_{1}, \beta_{2}, \ldots, \beta_{n}=$ coeficientes a serem estimados; $p_{0}, p_{1}, p_{2}, \ldots, p_{n}=$ potências a serem selecionadas para compor o Polinômio de Potências Fracionárias e Inteiras de Hradetzky.

O desempenho dos modelos de afilamento foi analisado de acordo com as seguintes estatísticas de ajuste e precisão: coeficiente de determinação ajustado $\left(R_{a j}^{2}\right)$, erro padrão relativo $(\operatorname{syx} \%)$ e análise gráfica dos resíduos em porcentagem. Além dessas estatísticas, para avaliar a acurácia das estimativas dos diâmetros, volume por seção e volume acumulado (da base da árvore até a posição relativa da altura) ao longo do fuste das árvores, realizadas com os modelos de afilamento, foram calculadas as estatísticas viés $(V)$ (Equação 2), média das diferenças $(M D)$ (Equação 3) e desvio padrão das diferenças $(D P D)$ (Equação 4).

$$
\begin{aligned}
& V=\frac{\sum_{=1}^{n} Y_{i}-\sum_{i=1}^{n} \hat{Y}_{i}}{n} \\
& M D=\frac{\sum_{i=1}^{n}\left|Y_{i}-\hat{Y}_{i}\right|}{n} \\
& D P D=\sqrt{\frac{\sum_{i=1}^{n}\left(Y_{i}-\hat{Y}_{i}\right)^{2}-\frac{\left(\sum_{i=1}^{n} Y_{i}-\widehat{Y}_{i}\right)^{2}}{n}}{n-p}}(\text { Equação 4) }
\end{aligned}
$$

em que: $Y_{i}=$ variável observada; $\hat{Y}_{i}=$ variável estimada; $n=$ número de observações; $p=$ número de coeficientes do modelo.

As estatísticas viés $(V)$, média das diferenças $(M D)$ e desvio padrão das diferenças $(D P D)$ foram calculadas segundo as posições relativas da altura das árvores: 0 a 10\%, 10 a 20\%, 20 a $30 \%$ e assim por diante, até 90 a $100 \%$. De posse dos valores de $V, M D$ e $D P D$ o modelo de afilamento de melhor desempenho para estimativa de diâmetro com casca, volume por seção e volume acumulado com casca foi selecionado para cada classe de altura relativa, nos sítios I, II e III, conforme realizado por Assis et al. (2002), Queiroz et al. (2006), Favalessa et al. (2012b) e Téo et al. (2013).
Como objetivou-se estudar a precisão dos modelos de afilamento para estimativa de diâmetros e volumes com casca a diferentes alturas das árvores, foram calculadas as estatísticas de ajuste e precisão, bem como, realizada a análise gráfica de resíduos, para essas variáveis. Os gráficos de resíduos das estimativas de diâmetro e volume com casca foram construídos sobre as alturas relativas $\left(h_{i} / h\right)$, visando analisar as estimativas ao longo do tronco das árvores de Eucalyptus grandis. A expressão para estimativa dos diâmetros a diferentes alturas pode ser encontrada isolando-se a variável $d_{i j}$ nos modelos descritos na Tabela 2 , já a expressão para a estimativa dos volumes totais das árvores pode ser obtida pela integral desses modelos.

De posse da função de afilamento de melhor desempenho para as árvores de Eucalyptus grandis, em cada classe de sítio, foi possível construir o gráfico do perfil do tronco médio para estas árvores e, por meio dele, analisar a forma dos seus fustes.

\section{RESULTADOS}

$\mathrm{Na}$ Tabela 3 estão apresentados os coeficientes das funções de afilamento ajustadas para estimar diâmetros e volume com casca, ao longo dos fustes das árvores de Eucalyptus grandis, por classe de sítio, aos 80 meses de idade. Todos os coeficientes estimados foram significativamente diferentes de zero $(\alpha=0,01)$ e os limites de seus intervalos de confiança, com $95 \%$ de probabilidade, não incluíram o valor zero (Tabela 3).Quanto à estimativa de diâmetros e volume por seção com casca ao longo do fuste, a equação de Kozak apresentou os menores valores de $R_{a j}^{2}$. e os maiores valores de erro padrão (syx\%), para todas as classes de sítio avaliadas (Tabela 4). A distribuição dos resíduos sobre a altura relativa pra estimar, tanto os diâmetros como os volumes por seção, indicaram tendência de superestimativa do diâmetro na base e no ápice, 
contudo, na porção intermediária houve tendência de subestimativa (Figuras 1 e 2). Este comportamento da equação de Kozak, o qual ocorreu para todas as classes de sítio, também foi demostrado pela estatística viés $(V)$, a qual apresentou valores negativos de 0 a $30 \%$ e de 70 a $100 \%$ da altura total, entretanto de 30 a $70 \%$, apresentou valores positivos.

A equação de Schöpfer apresentou valores intermediários entre Kozak e Hradetzky, tanto para $R_{a j}^{2}$, como para $s y x \%$, referente às estimativas de diâmetro e volume por seção com casca, em todas as classes de sítio (Tabela 4). Ao analisar a distribuição de resíduos da equação de Schöpfer, foi possível identificar tendenciosidade de subestimativa dos diâmetros com casca, nas posições de 10 a $30 \%$ da altura, em todas as classes de sítio (Figura 1). Entre 10 a $30 \%$ da altura total, foram observados valores de viés positivos mais acentuados.

Por fim, o melhor ajuste $\left(R_{a j}^{2}\right)$ e precisão $(s y x \%)$ para estimativa de diâmetros ao longo do fuste foi apresentado por Hradetzky, para todas as classes de sítio avaliadas (Tabela 4).
Em comparação com as demais equações, a de Hradetzky apresentou distribuição de resíduos mais uniforme para estimativa de diâmetros com casca, ao longo do fuste das árvores de Eucalyptus grandis, em todas as classes de sítio. No entanto, verifica-se o aumento da variabilidade dos resíduos com a altura relativa, na maior parte do fuste, independentemente do modelo de afilamento (Figura 1). A distribuição de resíduos referente à classe de sítio III apresenta uma série de valores negativos mais acentuados, os quais provêm de uma única árvore também visível na distribuição de resíduos das equações de Kozak e Schöpfer, com valores ainda mais discrepantes (Figura 1). Considerando de maneira conjunta as estatísticas viés $(V)$, média das diferenças $(M D)$ e desvio padrão das diferenças $(D P D)$, a equação de Hradetzky apresentou o melhor desempenho para estimar os diâmetros ao longo do fuste das árvores, em todas as classes de sítio e quase todas as alturas relativas, exceto de 50 a $60 \%$, na classe de sítio III (Tabelas 5 e 6).

Tabela 3. Ajuste das funções de afilamento por classe de sítio, para Eucalyptus grandis, Rio Verde, GO.

Table 3. Fitting of the taper functions by site class, for Eucalyptus grandis trees, Rio Verde, GO.

\begin{tabular}{|c|c|c|c|c|c|c|c|c|c|}
\hline Classe de Sítio & Função de Afilamento & & & & $\mathrm{Coe}$ & ientes & & & \\
\hline 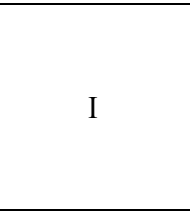 & $\begin{array}{c}\text { Kozak } \\
\text { Schöpfer } \\
\text { Hradetzky }\end{array}$ & $\begin{array}{c}\beta_{0} \\
1,1678 \\
\beta_{0} \\
1,1361 \\
\beta_{0} \\
1,2184 \\
\end{array}$ & $\begin{array}{c}\beta_{1} \\
-1,5820 \\
\beta_{1} \\
-3,0528 \\
\beta_{0,005} \\
-452,877 \\
\end{array}$ & $\begin{array}{c}\beta_{2} \\
0,4064 \\
\beta_{2} \\
15,3981 \\
\beta_{0,02} \\
682,201 \\
\end{array}$ & $\begin{array}{c}\beta_{3} \\
-38,3253 \\
\beta_{0,07} \\
-272,664 \\
\end{array}$ & $\begin{array}{c}\beta_{4} \\
40,5821 \\
\beta_{0,2} \\
44,7899 \\
\end{array}$ & $\begin{array}{c}\beta_{5} \\
-15,7423 \\
\beta_{1} \\
-2,4884 \\
\end{array}$ & $\begin{array}{c}\beta_{4} \\
-0,0737 \\
\end{array}$ & $\begin{array}{c}\beta_{100} \\
-0,1050 \\
\end{array}$ \\
\hline II & $\begin{array}{l}\text { Schöpfer } \\
\text { Hradetzky }\end{array}$ & $\begin{array}{c}\beta_{0} \\
1,1767 \\
\beta_{0} \\
1,1450 \\
\beta_{0} \\
1,2104 \\
\end{array}$ & $\begin{array}{c}\beta_{1} \\
-1,7273 \\
\beta_{1} \\
-3,1873 \\
\beta_{0,0001} \\
31278,0 \\
\end{array}$ & $\begin{array}{c}\beta_{2} \\
0,5631 \\
\beta_{2} \\
15,2358 \\
\beta_{0,005} \\
-69243,4 \\
\end{array}$ & $\begin{array}{c}\beta_{3} \\
-36,7670 \\
\beta_{0,01} \\
38528,0\end{array}$ & $\begin{array}{c}\beta_{4} \\
38,3218 \\
\beta_{0,1} \\
-718,244\end{array}$ & $\begin{array}{c}\beta_{5} \\
-14,7502 \\
\beta_{0,2} \\
157,963 \\
\end{array}$ & $\begin{array}{c}b_{1} \\
-3,3074\end{array}$ & $\begin{array}{c}\mathrm{b}_{25} \\
-0,1259 \\
\end{array}$ \\
\hline III & $\begin{array}{l}\text { Schöpfer } \\
\text { Hradetzky }\end{array}$ & $\begin{array}{c}\beta_{0} \\
1,1700 \\
\beta_{0} \\
1,1390 \\
\beta_{0} \\
1,1905 \\
\end{array}$ & $\begin{array}{c}\beta_{1} \\
-1,7306 \\
\beta_{1} \\
-3,1138 \\
\beta_{0,01} \\
0,7035 \\
\end{array}$ & $\begin{array}{c}\beta_{2} \\
0,5623 \\
\beta_{2} \\
15,0775 \\
\beta_{0,1} \\
-1,2001 \\
\end{array}$ & $\begin{array}{c}\beta_{3} \\
-36,9251 \\
\beta_{1} \\
0,4102 \\
\end{array}$ & $\begin{array}{c}\beta_{4} \\
38,7007 \\
\beta_{2} \\
-1,1747 \\
\end{array}$ & $\begin{array}{c}\beta_{5} \\
-14,8806 \\
\beta 5 \\
0,2006 \\
\end{array}$ & $\begin{array}{c}\beta_{100} \\
-0,1301 \\
\end{array}$ & \\
\hline
\end{tabular}

Tabela 4. Estatísticas de Ajuste e precisão das funções de afilamento para estimar diâmetro com casca (cm), volume por seção e volume acumulado com casca $\left(\mathrm{m}^{3}\right)$, por classe de sítio, para Eucalyptus grandis, Rio Verde, GO.

Table 4. Fitting and precision statistics of the taper functions to estimate diameter outside bark $(\mathrm{cm})$, volume per section and accumulated volume outside bark $\left(\mathrm{m}^{3}\right)$, by site classes, for Eucalyptus grandis, Rio Verde, GO.

\begin{tabular}{ccccccccccc}
\hline \multirow{2}{*}{ Função de Afilamento de Sítio I } & \multicolumn{3}{c}{ Classe de Sítio II } & \multicolumn{3}{c}{ Classe de Sítio III } \\
\cline { 3 - 11 } & \multirow{2}{*}{ Estatística } & $d_{c / c}$ & $v_{\text {sec. }}$ & $v_{\text {acum. }}$ & $d_{c / c}$ & $v_{\text {sec. }}$ & $v_{a c u m .}$ & $d_{c / c}$ & $v_{\text {sec. }}$ & $v_{a c u m .}$ \\
\hline \multirow{2}{*}{ Kozak } & $R_{a j .}^{2}$ & 0,979 & 0,979 & 0,994 & 0,972 & 0,972 & 0,992 & 0,977 & 0,971 & 0,990 \\
& $s y x \%$ & 6,08 & 11,47 & 6,00 & 6,88 & 13,12 & 6,90 & 6,25 & 13,27 & 7,68 \\
\multirow{2}{*}{ Schöpfer } & $R_{a j .}^{2}$ & 0,987 & 0,990 & 0,995 & 0,986 & 0,987 & 0,994 & 0,986 & 0,984 & 0,992 \\
& $s y x \%$ & 4,82 & 8,12 & 5,19 & 4,95 & 8,88 & 5,88 & 4,91 & 9,83 & 6,81 \\
\multirow{3}{*}{ Hradetzky } & $R_{a j .}^{2}$ & 0,991 & 0,991 & 0,995 & 0,988 & 0,989 & 0,994 & 0,988 & 0,985 & 0,992 \\
& $s y x \%$ & 4,05 & 7,63 & 5,18 & 4,44 & 8,33 & 5,89 & 4,59 & 9,70 & 6,85 \\
\hline
\end{tabular}

$d_{c / c}=$ diâmetro com casca $(\mathrm{cm}) ; v_{\text {seç. }}=$ volume por seção com casca $\left(\mathrm{m}^{3}\right) ; v_{a c u m}=$ volume acumulado com casca $\left(\mathrm{m}^{3}\right) ; R_{a j .}^{2}=$ coeficiente de determinação ajustado; $s y x \%=$ erro padrão relativo $(\%)$.

Os gráficos de resíduos das estimativas de volume por seção foram muito parecidos para as equações de Schöpfer e Hradetzky, porém a distribuição dos resíduos para a porção intermediária dos fustes das árvores da classe de sítio I e para a base dos fustes das árvores de sítio III mostrou-se mais equilibrada para a equação de Hradetzky (Figura 2).

Por outro lado, quando são analisadas as estimativas de volume somente da última seção do fuste, a equação de Hradetzky apresentou tendência de superestimativa mais acentuada do que a equação de Schöpfer (Figura 2 e Tabela 6).
Ao analisar o perfil dos fustes das árvores conforme a equação de Hradetzky (Figura 4), verifica-se grande variação de forma no ápice da árvore, principalmente para as classes de sítio I e III, as quais apresentaram as maiores tendenciosidades.

Quanto ao viés $(V)$, média das diferenças $(M D)$ e desvio padrão das diferenças $(D P D)$, constatou-se a superioridade da equação de Hradetzky para estimativa dos volumes por seção para a totalidade das posições relativas do fuste das árvores nas classes de sítio I e II e quase todas as posições relativas para o 
sítio III, exceto para as alturas relativas de 40 a $60 \%$, onde a equação de Schöpfer obteve maior exatidão (Tabelas 5 e 6).

Para o volume acumulado com casca, a equação de Kozak apresentou desempenho inferior, porém com estatísticas de ajuste e precisão mais próximas às demais equações de afilamento (Tabela 4). Já a distribuição de resíduos mostrou subestimativas do volume acumulado para as alturas relativas menores que $10 \%$ e resíduos mais uniformes à medida que a altura relativa aumenta para as classes de sítio I, II e III (Figura 3). Os valores de $V$ foram positivos apenas até $10 \%$ da altura total, a partir desta posição foram negativos indicando superestimativas do volume acumulado, também para todas as classes de sítio.
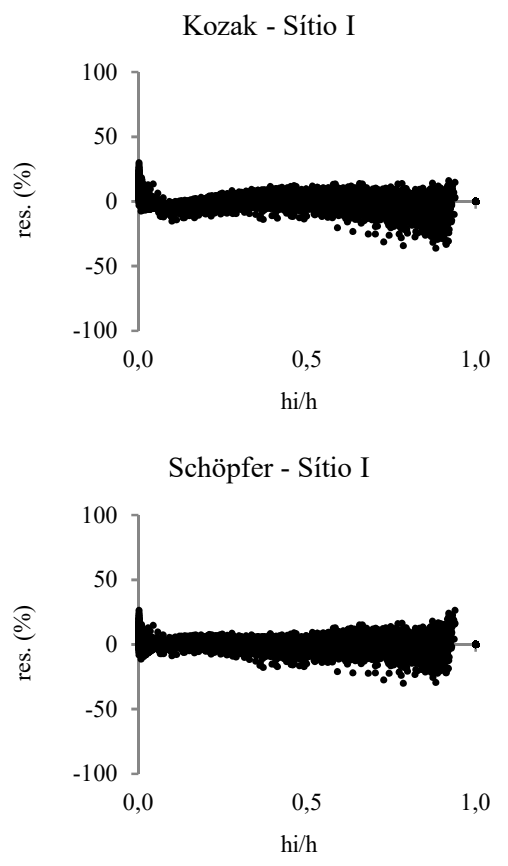

836

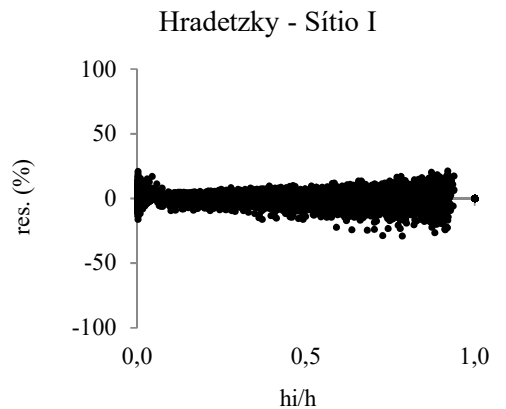

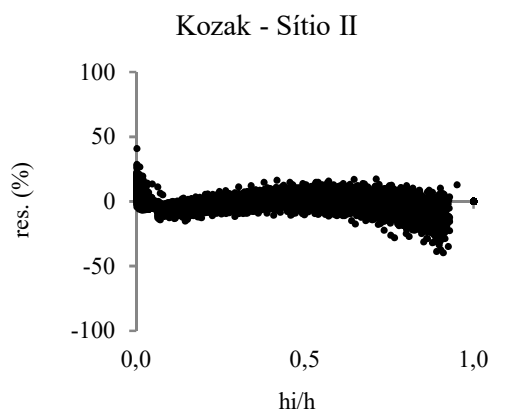
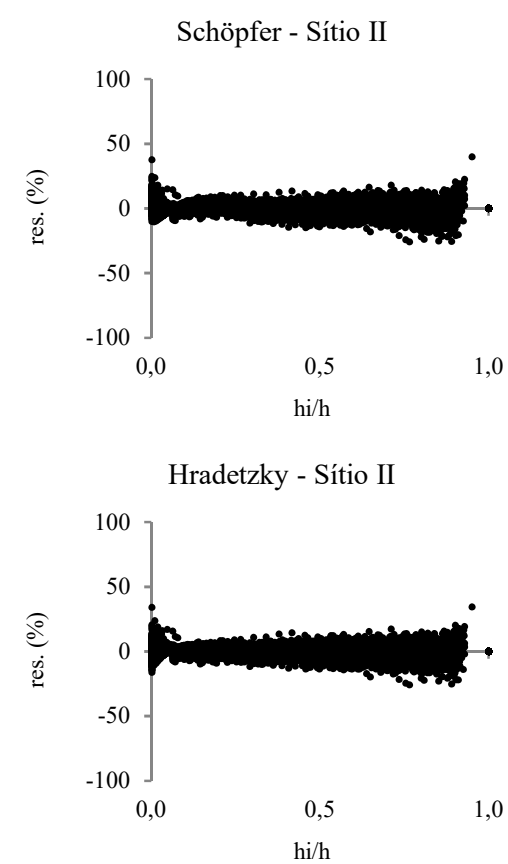

Kozak - Sítio III

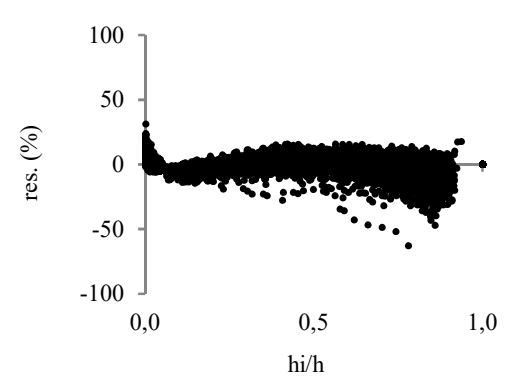

Schöpfer - Sítio III

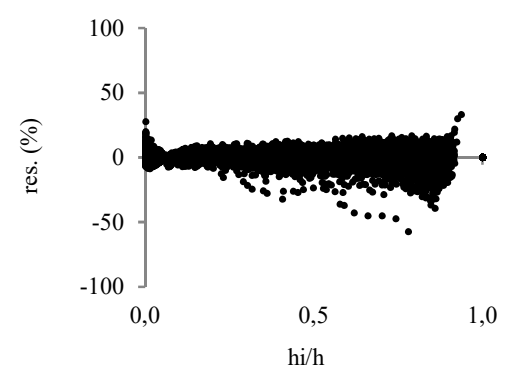

Hradetzky - Sítio III

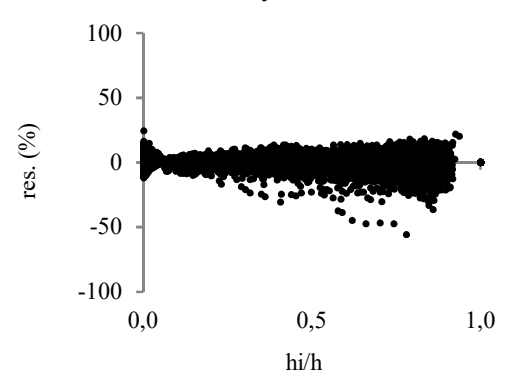

Figura 1. Distribuição de resíduos para estimativa de diâmetro com casca de árvores de Eucalyptus grandis, por classe de sítio, Rio Verde, GO.

Figure 1. Residue distribution for estimate diameter outside bark of Eucalyptus grandis trees, by site class, Rio Verde, GO.

As equações de Schöpfer e Hradetzky apresentaram os mesmos valores de $R_{a j .}^{2}$ e valores muito próximos de syx\% para estimativa de volume acumulado com casca, em todas as classes de sítio avaliadas (Tabela 4). Assim como ocorreu para

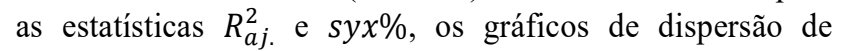
resíduos foram muito semelhantes para as equações de Schöpfer e Hradetzky. Para todas as classes de sítios, tanto Schöpfer como Hradetzky apresentaram maior amplitude de valores de resíduos para estimativa do volume acumulado na base dos troncos das árvores, com valores de resíduos positivos mais acentuados, indicando subestimativas (Figura 3).

Considerando o $V, M D$ e $D P D$, para as estimativas de volume acumulado por posição relativa, ao longo do fuste das árvores, verifica-se a superioridade da equação de Hradetzky, para as árvores da classe de sítio I e de Schöpfer, para a classe de sítio II (Tabelas 5 e 6). A equação de Kozak produziu as estimativas mais acuradas do volume acumulado, a partir de
90\% da altura relativa, para as árvores do sítio II, indicando o melhor desempenho para a estimativa do volume total, todavia este desempenho não se repete para as estimativas do volume ao longo do tronco (Tabela 5 e 6 ). Por fim, para as árvores da classe de sítio III, tanto Schöpfer quanto Hradetzky apresentaram os melhores desempenhos para estimar volumes acumulados em cinco alturas relativas (Tabela 6), entretanto a equação de Schöpfer pode ser considerada de melhor desempenho considerando as estatísticas $V, M D$ e $D P D$ (Tabela 5) e menor valor de syx\% (Tabela 4).

$\mathrm{Na}$ Figura 4 apresenta-se o perfil do fuste médio das árvores de Eucalyptus grandis, nas classes de sítio I, II e III, obtidos pelo Polinômio de Potências Fracionárias e Inteiras de Hradetzky, o qual foi a função de afilamento de melhor desempenho para estimativa de diâmetros ao longo do fuste (Tabelas 4, 5 e 6, Figura 1).

$\mathrm{O}$ traçado do perfil dos troncos parte dos valores de diâmetro na base do fuste de 18,8,18,2 e 17,7 cm, para as classes de sítio I, II e III, respectivamente. E findam-se nas 
alturas médias de $27,63,26,77$ e $25,57 \mathrm{~m}$, respectivamente para as classes de sítio I, II e III.

A taxa de afilamento média das árvores de Eucalyptus grandis foi de $0,68,0,68$ e $0,69 \mathrm{~cm} / \mathrm{m}$, para as classes de sítio I, II e III, respectivamente. Considerando-se somente a porção do fuste entre 20 e $80 \%$, ou seja, somente sua porção intermediária, tem-se um afilamento de 0,49, 0,48 e 0,52 $\mathrm{cm} / \mathrm{m}$, indicando que a maior conicidade dos fustes das árvores na classe de sítio III, proporcionando maior afilamento e, consequentemente, pior forma (Figura 4).
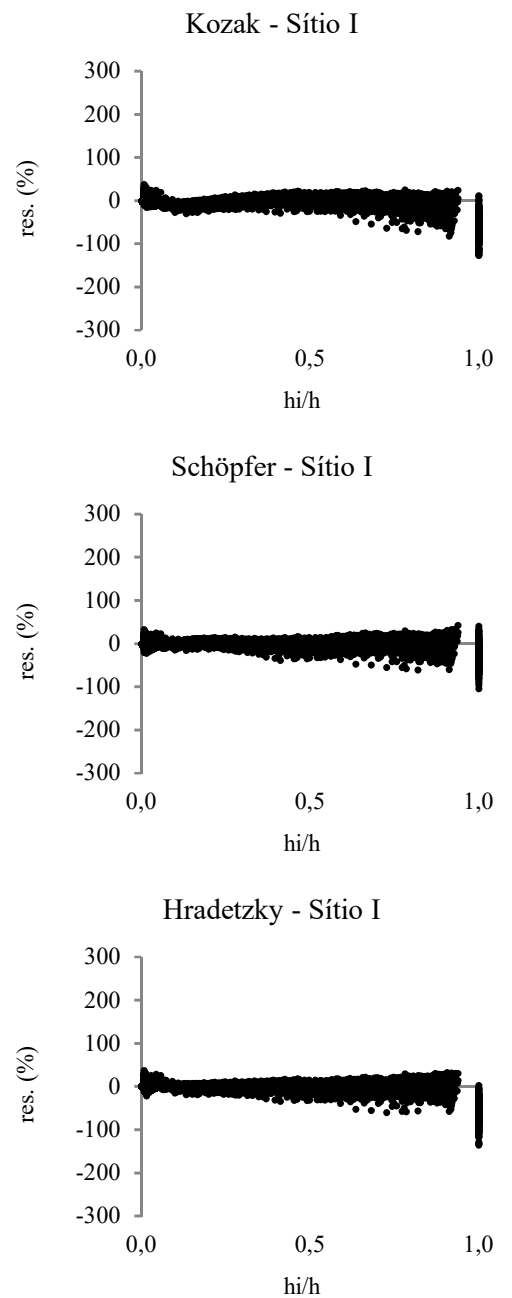

Kozak - Sítio II

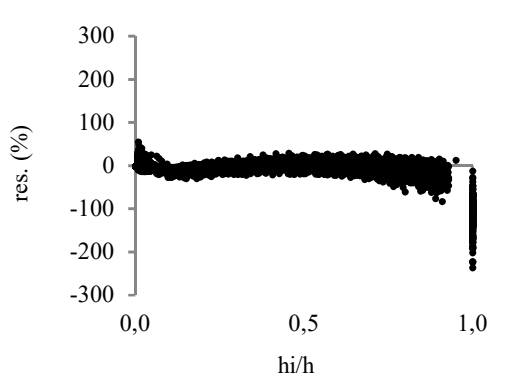

Schöpfer - Sítio II
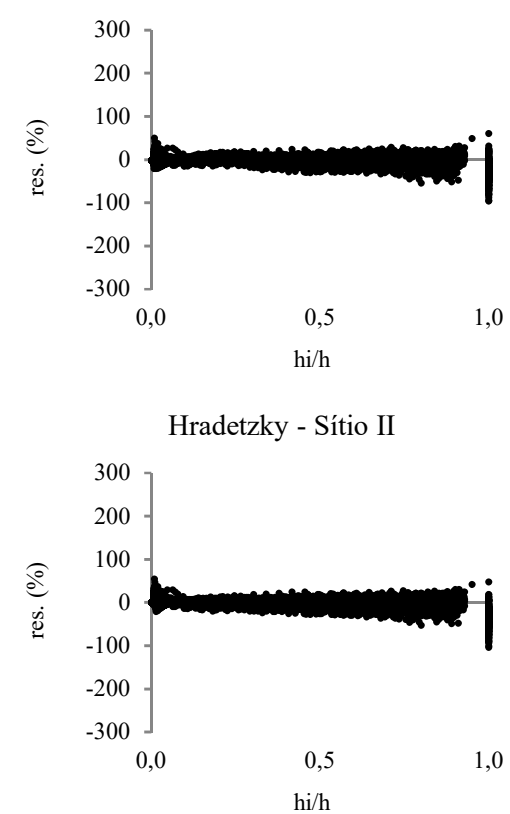

Kozak - Sítio III

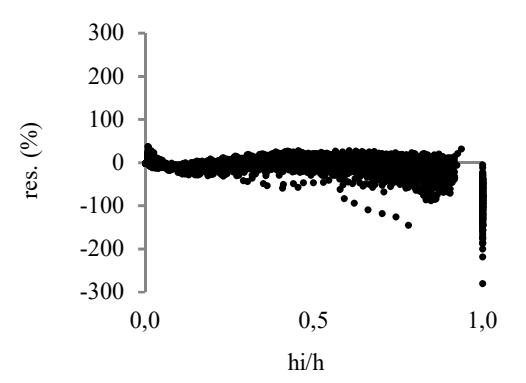

Schöpfer - Sítio III

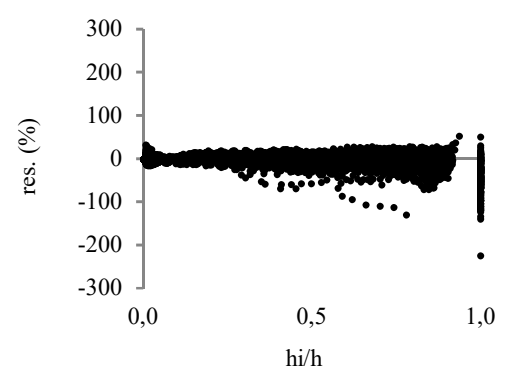

Hradetzky - Sítio III

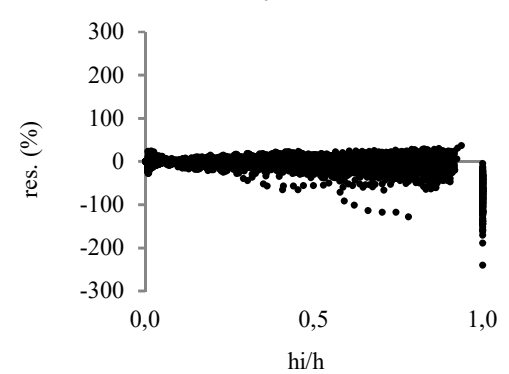

Figura 2. Distribuição de resíduos das funções de afilamento, para estimativa de volume por seção com casca de árvores de Eucalyptus grandis, por classe de sítio, Rio Verde, GO.

Figure 2. Residue distribution of the taper functions, for estimate volume per section outside bark of Eucalyptus grandis trees, by site class, Rio Verde, GO.

\section{DISCUSSÃO}

Em concordância aos resultados encontrados neste estudo, Miguel et al. (2011) destacaram o modelo de Hradetzky com as melhores estatísticas para estimativa de diâmetros ao longo do fuste de Eucalyptus urophylla S. T. Blake, no estado de Goiás, seguido de perto pelo modelo de Schöpfer e, por último, Kozak. Favalessa et al. (2012a) recomendaram o modelo de Hradetzky para estimativa de diâmetros ao longo do fuste e o modelo de Schöpfer para estimativa de volumes ao longo do fuste de Tectona grandis, no Estado do Mato Grosso. Figueiredo et al. (2006) reportaram o bom desempenho do modelo de Hradetzky para retratar as extremidades inferiores e superiores dos fustes de Tectona grandis L.f., no Mato Grosso e no estado do Acre, respectivamente.

Diversos autores destacaram a superioridade do modelo de Hradetzky para estimativa de diâmetros ao longo do tronco de Pinus spp., nos Estados do Paraná e Santa Catarina (ASSIS et al., 2002; KOHLER et al., 2013; TÉO et al., 2013; DAVID et al., 2014). Assis et al. (2002) reportaram que o modelo de Schöpfer mostrou estimativas tendenciosas de diâmetros ao longo do fuste de Pinus taeda, na região de Jaguariaíva - PR. Por outro lado, Souza et al. (2008) recomendaram o modelo de Schöpfer para estimativas de diâmetros ao longo do fuste de Pinus taeda, em Santa Catarina, entretanto esses autores não testaram o modelo de Hradetzky.

Por outro lado, Figueiredo et al. (2006) relataram a dificuldade do modelo de Schöpfer representar as extremidades de árvores de Tectona grandis, propiciando piores estimativas de volume. De acordo com Assis et al. (2002) e Eisfeld et al. (2004), o modelo de Hradetzky apresentou as melhores estimativas de volumes totais e parciais para Pinus taeda, no Estado do Paraná. De acordo com Queiroz et al. (2006), o modelo de Hradetzky foi o mais acurado para estimativa do volume acumulado de fustes de Mimosa scabrella Bentham, na região metropolitana de Curitiba - PR, principalmente nas posições inferiores do fuste, até $60 \%$ da altura. Resultados semelhantes aos de Queiroz et al. (2006) foram encontrados neste estudo para estimativa do volume acumulado dos fustes de Eucalyptus grandis, nas classes de sítio I e II. 
Kozak - Sítio I

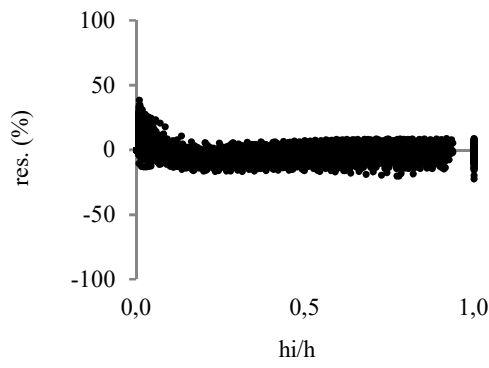

Schöpfer - Sítio I

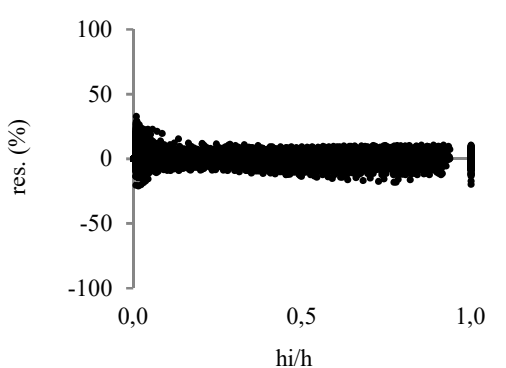

Hradetzky - Sítio I

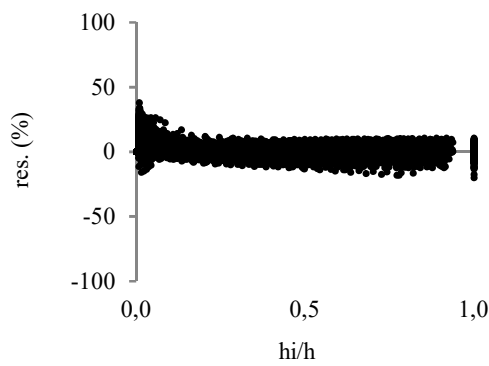

Kozak - Sítio II

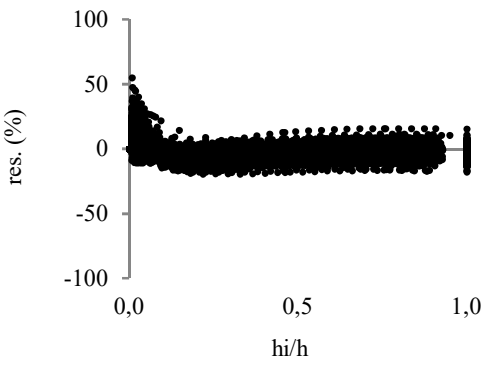

Schöpfer - Sítio II

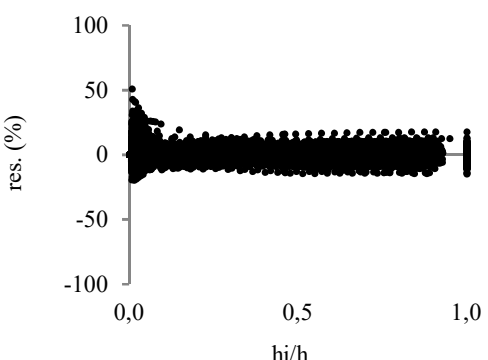

hi/h

Hradetzky - Sítio II

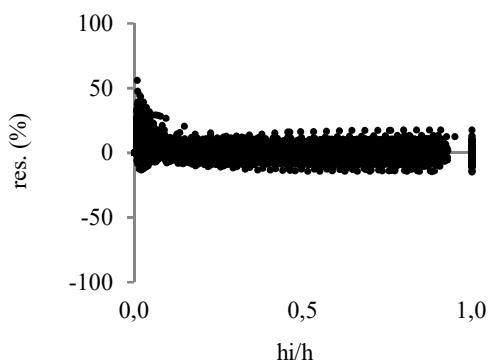

Kozak - Sítio III

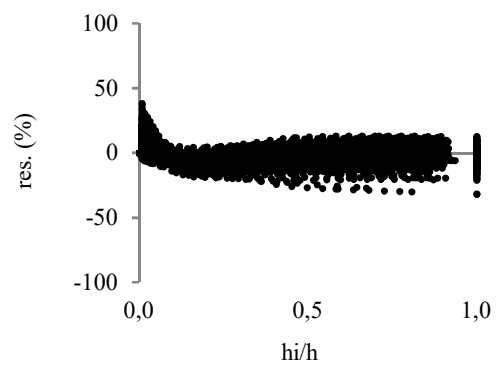

Schöpfer - Sítio III

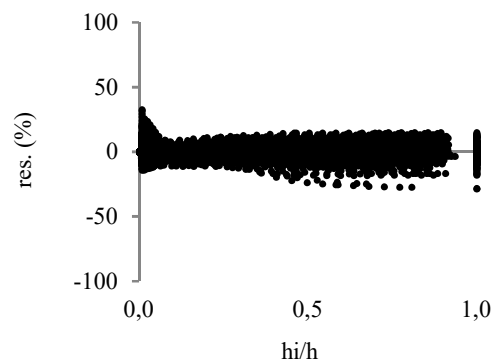

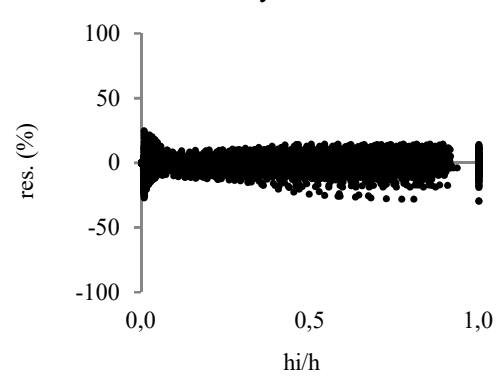

Figura 3. Distribuição de resíduos para estimativa de volume acumulado com casca de árvores de Eucalyptus grandis, por classe de sítio, Rio Verde, GO.

Figure 3. Residue distribution for estimate accumulated volume outside bark of Eucalyptus grandis trees, by site class, Rio Verde, GO.

A porção basal dos fustes das árvores de Eucalyptus grandis foi semelhante independente das classes de sítio, assumindo forma próxima a um sólido geométrico do tipo neiloide. Já, na porção intermediária dos fustes, observa-se maior aproximação entre as classes de sítio I e II, para as quais o perfil do fuste assemelha-se a um paraboloide, representado por um traçado mais côncavo ao longo do eixo longitudinal, enquanto o perfil do fuste das árvores do sítio III apresenta-se mais cônico em sua porção intermediária. Por fim, no topo dos perfis nota-se maior semelhança entre as classes de sítio I e III, com traçado mais acentuado, indicando uma diminuição dos diâmetros mais abrupta quando comparados ao perfil do fuste das árvores do sítio II. Isso se deve à seleção de potências de grau mais elevado pelo procedimento de regressão passo a passo, para compor o Polinômio de Potências Fracionárias e Inteiras de Hradetzky, nas classes de sítio I e III (Tabela 3 e Figura 4).

Em média, quanto melhor a classe de sítio, maiores são as árvores de Eucalyptus grandis, tanto em altura como em diâmetro (Figura 4), provavelmente devido aos maiores e mais rápidos incrementos durante as primeiras fases do crescimento.

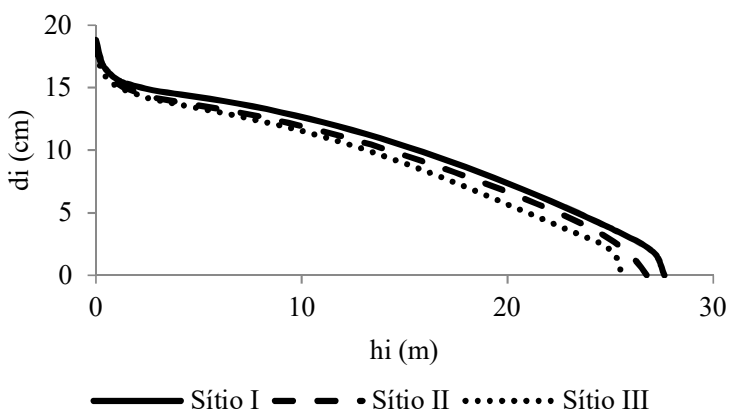

Figura 4. Perfil do fuste descrito pela função de afilamento de melhor desempenho, para estimar diâmetros ao longo do fuste de Eucalyptus grandis, por classe de sítio, Rio Verde, GO.

Figure 4. Stem profile described by the best performance taper function, for estimate diameters throughout stem of Eucalyptus grandis trees, by site class, Rio Verde, GO.

Quando comparadas as diferenças relativas (\%) entre as dimensões médias das árvores nas diferentes classes de sítio, verificou-se que há maior diferença entre as alturas das árvores do que entre os diâmetros, da classe de sítio III para as classes de sítio I e II. Assim, a qualidade do sítio exerceu efeito maior no crescimento em altura das árvores e menor no crescimento 
em diâmetro, fazendo as árvores na classe de sítio III diâmetro. De maneira semelhante aos resultados encontrados apresentarem maior afilamento. Botelho et al. (1996) para sítios de melhor qualidade, Ferreira; Silva (2002) analisaram o crescimento inicial de seis espécies florestais em concluíram que a adubação melhorou levemente a forma dos diferentes sítios, em Itutinga - MG, e encontraram diferenças fustes de Eucalyptus grandis, em Brotas - SP, devido ao seu mais significativas para o crescimento em altura entre os efeito no crescimento em altura das árvores. diferentes sítios, quando comparado ao crescimento em

Tabela 5. Viés (V), média das diferenças (MD) e desvio padrão das diferenças (DPD) do modelo de melhor desempenho estatístico para estimar diâmetro com casca $(\mathrm{cm})$,volume por seção com casca $\left(\mathrm{m}^{3}\right)$ e volume acumulado com casca $\left(\mathrm{m}^{3}\right)$ ao longo do fuste e por classe de sítio, para Eucalyptus grandis, Rio Verde, GO.

Table 5. Bias (V), mean of differences (MD) and standard deviation of the differences (DPD) of the best statistical performance model to estimate diameter outside bark $(\mathrm{cm})$, volume per section outside bark $\left(\mathrm{m}^{3}\right)$ and accumulated volume outside bark $\left(\mathrm{m}^{3}\right)$ throughout stem and by site classes, for Eucalyptus grandis, Rio Verde, GO.

\begin{tabular}{|c|c|c|c|c|c|c|c|c|c|}
\hline \multirow{2}{*}{ Altura relativa } & \multicolumn{3}{|c|}{$\mathrm{d}_{\mathrm{c} / \mathrm{c}}$} & \multicolumn{3}{|c|}{$\mathrm{v}_{\text {seç. }}$} & \multicolumn{3}{|c|}{$\mathrm{v}_{\text {acum. }}$} \\
\hline & $\mathrm{V}$ & MD & DPD & $\mathrm{V}$ & MD & DPD & $\mathrm{V}$ & MD & DPD \\
\hline \multicolumn{10}{|c|}{ Sítio I } \\
\hline & \multicolumn{3}{|c|}{ Hradetzky } & \multicolumn{3}{|c|}{ Hradetzky } & \multicolumn{3}{|c|}{ Hradetzky } \\
\hline $0,0-9,9 \%$ & $-0,006943$ & 0,099078 & 0,308786 & 0,000016 & 0,000061 & 0,000212 & 0,000141 & 0,000223 & 0,000594 \\
\hline $10,0-19,9 \%$ & $-0,003107$ & 0,021986 & 0,102085 & $-0,000006$ & 0,000048 & 0,000230 & 0,000032 & 0,000162 & 0,000768 \\
\hline $20,0-29,9 \%$ & 0,001334 & 0,026086 & 0,114581 & 0,000002 & 0,000055 & 0,000247 & 0,000028 & 0,000290 & 0,001353 \\
\hline $30,0-39,9 \%$ & 0,002709 & 0,028623 & 0,126059 & 0,000007 & 0,000057 & 0,000252 & 0,000043 & 0,000412 & 0,001902 \\
\hline $40,0-49,9 \%$ & $-0,002075$ & 0,039065 & 0,149755 & 0,000003 & 0,000055 & 0,000232 & 0,000079 & 0,000725 & 0,002909 \\
\hline $9 \%$ & 0,004030 & 0,030468 & 0,131806 & 0,000006 & 0,000048 & 0,000213 & 0,000072 & 0,000651 & 0,003013 \\
\hline $9 \%$ & $-0,002867$ & 0,029049 & 0,124072 & 0,000001 & 0,000040 & 0,000174 & 0,000092 & 0,000755 & 0,003411 \\
\hline $70,0-$ & 0,000953 & 0,030652 & 0,123415 & 0,000000 & 0,000029 & 0,000125 & 0,000120 & 0,000950 & 0,003992 \\
\hline $80,0-89,9 \%$ & $-0,000624$ & 0,025687 & 0,109028 & 0,000001 & 0,000018 & 0,000083 & 0,000131 & 0,000927 & 0,004106 \\
\hline 90,0 & $-0,000800$ & 0,004819 & 0,048410 & 0,000000 & 0,000002 & 0,000028 & 0,000061 & 0,000220 & 0,002172 \\
\hline \multicolumn{10}{|c|}{ Sítio II } \\
\hline & \multicolumn{3}{|c|}{ Hradetzky } & \multicolumn{3}{|c|}{ Hradetzky } & \multicolumn{3}{|c|}{ Schöpfer } \\
\hline 0 & $-0,010387$ & 0,111781 & 0,341446 & 0014 & 0,000064 & 0,000219 & $-0,000063$ & 0,000246 & 0,000757 \\
\hline 10,0 & 0,001701 & 0,025964 & 0,112025 & 0,000003 & 0,000055 & 0,000239 & $-0,000062$ & 0,000195 & 0,000881 \\
\hline 20,0 & 0,000092 & 0,026914 & 0,118285 & 0,000003 & 0,000055 & 0,000248 & 0,000062 &, 000302 & 0,001362 \\
\hline $9 \%$ & $-0,003894$ & 0,029074 & 27535 & $-0,000006$ & 0,000055 & & & 000432 & 0,001928 \\
\hline & $-0,000975$ & 0,040843 & 0,154480 & 0,000003 & 0,000053 & 0,000224 & 0,000023 & 0,000721 & 0,002837 \\
\hline $9 \%$ & 0,006294 & 0,032884 & 0,140691 & 0,000011 & 0,000051 & 0,000221 & 0,000009 & 0,000646 & 0,002897 \\
\hline $9 \%$ & 0,002327 & 0,029688 & 0,124605 & 0,000008 & 0,000038 & 0,000167 & 0,000064 & 0,000766 & 0,003399 \\
\hline $9 \%$ & 0,000741 & 0,031258 & 0,122792 & 0,000003 & 0,000028 & 0,000120 & 0,000165 & 0,000958 & 0,003983 \\
\hline $9 \%$ & $-0,004662$ & 0,022501 & 0,098549 & $-0,000003$ & 0,000017 & 0,000077 & 0,000140 & 0,000909 & 0,004038 \\
\hline $90,0-100 \%$ & 0,001767 & 0,003734 & 0,042495 & 0,000000 & 0,000001 & 0,000018 & 0,000073 & 0,000159 & 0,001834 \\
\hline \multicolumn{10}{|c|}{ Sítio III } \\
\hline & \multicolumn{3}{|c|}{ Hradetzky } & \multicolumn{3}{|c|}{ Hradetzky } & \multicolumn{3}{|c|}{ Schöpfer } \\
\hline & $-0,006193$ & 0,096537 & 0,283794 & $-0,000014$ & 0,000048 & 0,00 & $-0,00$ & 0,000191 & 0,000573 \\
\hline $10,0-19,9 \%$ & $-0,002265$ & 0,027381 & 0,119406 & $-0,000009$ & 0,000056 & 0,000251 & $-0,000041$ & 0,000172 & 0,000804 \\
\hline $20,0-29,9 \%$ & 0,000602 & 0,028075 & 0,128699 & 0,000003 & 0,000056 & 0,000260 & 0,000061 & 0,000271 & 0,001318 \\
\hline $30,0-39,9 \%$ & $-0,000074$ & 0,034290 & 0,156421 & 0,000000 & 0,000062 & 0,000287 & 0,000049 & 0,000402 & 0,001940 \\
\hline $40,0-49,9 \%$ & 0,005269 & 0,051212 & 0,191066 & 0,000011 & 0,000066 & 0,000276 & 0,000041 & 0,000747 & 0,003033 \\
\hline $50,0-59,9 \%$ & $-0,005232$ & 0,033589 & 0,152918 & $-0,000005$ & 0,000050 & 0,000227 & 0,000011 & 0,000678 & 0,003183 \\
\hline $60,0-69,9 \%$ & $-0,000485$ & 0,034279 & 0,147994 & 0,000000 & 0,000042 & 0,000185 & 0,000035 & 0,000820 & 0,003653 \\
\hline $70,0-79,9 \%$ & 0,001954 & 0,036675 & 0,149465 & 0,000001 & 0,000030 & 0,000134 & 0,000111 & 0,001021 & 0,004274 \\
\hline $80,0-89,9 \%$ & $-0,002937$ & 0,026088 & 0,119504 & 0,000001 & 0,000017 & 0,000085 & 0,000142 & 0,000879 & 0,004134 \\
\hline $90,0-100 \%$ & 0,000189 & 0,001684 & 0,029755 & 0,000000 & 0,000001 & 0,000015 & 0,000011 & 0,000060 & 0,001220 \\
\hline
\end{tabular}

$\mathrm{d}_{\mathrm{c} / \mathrm{c}}=$ diâmetro com casca $(\mathrm{cm}) ; \mathrm{v}_{\text {seç. }}=$ volume por seção com casca $\left(\mathrm{m}^{3}\right) ; \mathrm{v}_{\text {acum. }}=$ volume acumulado com casca $\left(\mathrm{m}^{3}\right)$.

\section{CONCLUSÕES}

A função de afilamento mais acurada para estimar os diâmetros e volumes por seção com casca ao longo do fuste de Eucalyptus grandis, em Rio Verde - GO, foi o Polinômio de Potências Fracionárias e Inteiras de Hradetzky, para todas as classes de sítio testadas.

Para estimar os volumes acumulados com casca, ao longo do fuste de Eucalyptus grandis, a função de afilamento de melhor desempenho foi o Polinômio do $5^{\circ}$ Grau para as árvores das classes de sítio II e III, e o Polinômio de Potências Fracionárias e Inteiras de Hradetzky, para as árvores da classe de sítio I.
Os fustes das árvores de Eucalyptus grandis apresentam menor afilamento e, portanto, melhor forma nos sítios de melhor qualidade (classes I e II), por outro lado, apresentam maior conicidade e pior forma na classe de sítio III.

\section{REFERÊNCIAS}

ALVARES, C. A.; STAPE, J. L.; SENTELHAS, P. C.; GONÇALVES, J. L. M.; SPAROVEK, G. Köppen's climate classification map for Brazil. Meteorologische Zeitschrift, Stuttgart, v. 22, n. 6, p. 711-728, 2013. DOI: https://dx.doi.org/10.1127/0941-2948/2013/0507 
Tabela 6. Seleção das funções de afilamento para estimativas de diâmetros, volume por seção e volume acumulado com casca, ao longo do fuste de árvores de Eucalyptus grandis, Rio Verde, GO.

Table 6. Selection of the taper functions for estimate diameters, volume per section and accumulated volume outside bark, throughout stem of Eucalyptus grandis trees, Rio Verde, GO.

\begin{tabular}{cccccccccc}
\hline \multirow{2}{*}{ Altura Relativa (\%) } & \multicolumn{3}{c}{ Classe de Sítio I } & \multicolumn{3}{c}{ Classe de Sítio II } & \multicolumn{3}{c}{ Classe de Sítio III } \\
\cline { 2 - 9 } & $d_{c / c}$ & $v_{\text {seç. }}$ & $v_{\text {acum. }}$ & $d_{c / c}$ & $v_{\text {seç. }}$ & $v_{\text {acum. }}$ & $d_{c / c}$ & $v_{\text {seç. }}$ & $v_{a c u m .}$ \\
\hline $0,0-9,9 \%$ & Hrad & Hrad & Hrad & Hrad & Hrad & Hrad & Hrad & Hrad & Schö \\
$10,0-19,9 \%$ & Hrad & Hrad & Hrad & Hrad & Hrad & Hrad & Hrad & Hrad & Schö \\
$20,0-29,9 \%$ & Hrad & Hrad & Hrad & Hrad & Hrad & Hrad & Hrad & Hrad & Hrad \\
$30,0-39,9 \%$ & Hrad & Hrad & Hrad & Hrad & Hrad & Hrad & Hrad & Hrad & Schö \\
$40,0-49,9 \%$ & Hrad & Hrad & Schö & Hrad & Hrad & Schö & Hrad & Schö & Hrad \\
$50,0-59,9 \%$ & Hrad & Hrad & Schö & Hrad & Hrad & Schö & Schö & Schö & Schö \\
$60,0-69,9 \%$ & Hrad & Hrad & Hrad & Hrad & Hrad & Schö & Hrad & Hrad & Schö \\
$70,0-79,9 \%$ & Hrad & Hrad & Hrad & Hrad & Hrad & Schö & Hrad & Hrad & Hrad \\
$80,0-89,9 \%$ & Hrad & Hrad & Hrad & Hrad & Hrad & Schö & Hrad & Hrad & Hrad \\
$90,0-100,0 \%$ & Hrad & Hrad & Hrad & Hrad & Hrad & Koz & Hrad & Hrad & Hrad \\
\hline
\end{tabular}

$\overline{d_{c / c}}=$ diâmetro com casca $(\mathrm{cm}) ; v_{\text {sec. }}=$ volume por seção com casca $\left(\mathrm{m}^{3}\right) ; v_{\text {acum. }}=$ volume acumulado com casca $\left(\mathrm{m}^{3}\right) ;$ Hrad = Hradetzky, Polinômio de Potências Fracionárias e Inteiras; Schö = Schöpfer, Polinômio de $5^{\circ} \mathrm{Grau}$; Koz $=$ Kozak, Polinômio de $2^{\circ} \mathrm{Grau}$.

AHRENS, S.; HOLBERT, D. Uma função para forma de tronco e volume de Pinus taeda L. Boletim de Pesquisa Florestal, Colombo, n. 3, p. 37-68, 1981.

ASSIS, A. L. de; SCOLFORO, J. R. S.; MELlO, J. M. de; OLIVEIRA, A. D. de. Avaliação de modelos polinomiais não-segmentados na estimativa de diâmetros e volumes comerciais de Pinus taeda. Ciência Florestal, Santa Maria, v. 12, n. 1, p. 89-107, 2002. DOI: http://dx.doi.org/10.5902/198050981704

BOTELHO, S. A.; DAVIDE, A. C.; FARIA, J. M. R. Desenvolvimento inicial de seis espécies florestais nativas em dois sítios, na região Sul de Minas Gerais. Cerne, Lavras, v. 2, n. 1, p. 4-13, 1996.

DAVID, H. C.; MARINHESKI FILHO, A.; PELISSARI, A. L.; PÉLlICO NETTO, S.; ARAÚJO, E. J. G. de; BAUM, L. Critérios de estratificação para o ajuste de funções de afilamentoem fustes de pinus. Pesquisa Florestal Brasileira, Colombo, v. 34, n. 79, p. 197-206, 2014. DOI: https://dx.doi.org/10.4336/2014.pfb.34.79.659

EISFELD, R. L.; MELLO, A. A.; SANQUETTA, C. R.; WEBER, K. S. Avaliação de modelos polinomiais na estimativa de volume total e por sortimento de Pinus taeda. Brasil Florestal, Brasília, v. 23, n. 79, p. 9-15, 2004.

EISFELD, R. L.; VIGOLO, D. Z.; SANQUETTA, C. R.; MELLO, A. A. Modelo de Hradetzky aplicado à estimativa do volume total para Araucaria angustifolia (Bert.) O. Ktze. Ambiência, Guarapuava, v. 4, n. 1, p. 5166, 2008.

FAVALESSA, C. M. C.; UBIALLI, J. A.; CALDEIRA, S. F.; DRESCHER, R. Funções de afilamento não segmentadas e segmentadas para Tectona grandis na região Centro-Sul matogrossense. Pesquisa Florestal Brasileira, Colombo, v. $32, \quad$ n. $72, \quad$ p. 373-387, 2012a. DOI: https://dx.doi.org/10.4336/2012.pfb.32.72.373

FAVALESSA, C. M. C.; UBIALLI, J. A.; CALDEIRA, S. F.; DRESCHER, R.; ACOSTA, F. C. Equações de sortimentos para Tectona grandis na região Centro-Sul de Mato Grosso. Pesquisa Florestal Brasileira, Colombo, v. 32, n. 72, p. 389-399, 2012b. DOI: https://dx.doi.org/10.4336/2012.pfb.32.72.389

FERREIRA, C. A.; SILVA, H. D. da. Afilamento e forma do tronco de árvores de Eucalyptus grandis e Eucalyptus saligna e suas variações com a adubação. Boletim de Pesquisa Florestal, Colombo, n. 44, p. 87-106, 2002.
FIGUEIREDO FILHO, A.; KOHLER, S. V.; FELDE, J. L.; DIAS, A. N. Dinâmica do afilamento do tronco e da produção de madeira em plantios de Araucariaangustifolia. Cerne, Lavras, v. 20, n. 4, p. 595603, 2014.

DOI: http://dx.doi.org/10.1590/01047760201420041386

FIGUEIREDO, E. O.; SCOLFORO, J. R. S.; OLIVEIRA, A. D. de. Seleção de modelos polinomiais para representar o perfil e volume do fuste de Tectona grandis L. f. Acta Amazonica, Manaus, v. 36, n. 4, p. 465-482, 2006. DOI: http://dx.doi.org/10.1590/S0044-59672006000400008

KOHLER, S. V.; KOEHLER, H. S.; FIGUEIREDO FILHO, A; ARCE, J. E.; MACHADO, S. A. Evolution of tree stem taper in Pinus taeda stands. Ciência Rural, Santa Maria, v. $46, \quad$ n. 7, p. 1185-1191, 2016. DOI: http://dx.doi.org/10.1590/0103-8478cr20140021

KOHLER, S. V.; KOEHLER, H. S.; FIGUEIREDO FILHO, A. Modelos de Afilamento para Pinus taeda por classe de idade. Floresta e Ambiente, Seropédica, v. 20, n. 4, p. 470-479 2013.

DOI: http://dx.doi.org/10.4322/floram.2013.039

LANSSANOVA, L. R.; UBIALLI, J. A.; ARCE, J. E.; PELISSARI, A. L.; FAVALESSA, C. M. C.; DRESCHER, R. Avaliação de funções de afilamento para estimativa de diâmetro de espécies florestais comerciais do bioma amazônico mato-grossense. Floresta, Curitiba, v. 43, n. 2, p. 215-224, 2013. DOI: http://dx.doi.org/10.5380/rf.v43i2.26518

MIGUEL, E. P.; MACHADO, S. A.; FIGUEIREDO FILHO, A.; ARCE, J. E. Modelos polinomiais para representar o perfil e o volume do fuste de Eucalyptus urophylla na região Norte do Estado de Goiás. Floresta, Curitiba, v. 41, n. 2, p. 2011. DOI: http://dx.doi.org/10.5380/rf.v41i2.21883

MÔRA, R.; SILVA, G. F. da; GONÇALVES, F. G.; SOARES, C. P. B.; CHICHORRO, J. F.; CURTO, R. D. A. Análise de diferentes formas de ajuste de funções de afilamento. Scientia Forestalis, Piracicaba, v. 42, n. 102, p. 237-249, 2014.

NOGUEIRA, G. S.; LEITE, H. G.; REIS, G. G.; MOREIRA, A. M. Influência do espaçamento inicial sobre a forma do fuste de árvores de Pinus taeda L. Revista Árvore, Viçosa, v. 32, n. 5, p. 855-860, 2008. DOI: http://dx.doi.org/10.1590/S0100-67622008000500010 
QUEIROZ, D.; MACHADO, S. A.; FIGUEIREDO FILHO, A.; ARCE, J. E.; KOEHLER, H. S. Avaliação e validação de funções de afilamento para Mimosa scabrella Bentham em povoamentos da região metropolitana de Curitiba/PR. Floresta, Curitiba, v. 36, n. 2, p. 183-199, 2006. DOI: http://dx.doi.org/10.5380/rf.v36i2.6461

QUEIROZ, D.; MACHADO, S. A.; FIGUEIREDO FILHO, A.; ARCE, J. E.; KOEHLER, H. S. Identidade de modelos em funções de afilamento para Mimosa scabrella Bentham em povoamentos nativos da região metropolitana de Curitiba/PR. Floresta, Curitiba, v. 38, n. $\begin{array}{llll}2, & \text { p. } & 339-349, & 2008\end{array}$ DOI: http://dx.doi.org/10.5380/rf.v38i2.11629

SOUZA, C. A. M. de; CHASSOT, T.; FINGER, C. A. G.; SCHNEIDER, P. R.; FLEIG, F. D. Modelos de afilamento DOI: http://dx.doi.org/10.5380/rf.v43i3.30320

TONG, Q. J.; ZHANG, S. Y. Stem form variations in the natural stands of major commercial softwoods in eastern Canada. Forest Ecology and Management, Amsterdam, v. 256, n. $6, \quad$ p. $1303-1310,2008$. DOI: https://dx.doi.org/10.1016/j.foreco.2008.06.028

YOSHITANI JUNIOR, M.; NAKAJIMA, N. Y.; ARCE, J. E.; MACHADO, S. A.; DRUSZCZ, J. P.; HOSOKAWA, R. T.; MELLO, A. A. de. Funções de afilamento para plantios desbastados de Pinus taeda. Floresta, Curitiba, v. 42, n. 1, p. $169-176$, 2012. para o sortimento do fuste de Pinus taeda L. Ciência Rural, Santa Maria, v. 38, n. 9, p. 2506-2511, 2008. DOI: http://dx.doi.org/10.1590/S0103-84782008000900014

SOUZA, C. A. M. de; FINGER, C. A. G.; SCHNEIDER, P. R.; SILVA, G. F. da; THOMAS, C. Eficiência de um modelo de afilamento ajustado sem e com estratificação por classe de quociente de forma para formação dos sortimentos de Pinus taeda L. Ciência Florestal, Santa Maria, v. 22, n. 1, p. 125-135, 2012. DOI: http://dx.doi.org/10.5902/198050985085

TÉO, S. J.; MARCON, A.; EHLERS, T.; BIANCHI, J. C.; PELOSO, A.; NAVA, P. R.; COSTA, R. H. da. Modelos de afilamento para Pinus elliottii em diferentes idades, na região de Caçador, SC. Floresta, Curitiba, v. 43, n. 3, p. 439-452, 2013. 